\title{
Reconstruction of the hazardous flood of 2014 in Magadan city based on coupled hydrometeorological modelling
}

\author{
Viktoriia Kurovskaia ${ }^{1 *}$, Olga Makarieva ${ }^{2,3}$, Nataliia Nesterova $^{3,4}$, Andrey Shikhov ${ }^{5}$, and \\ Tatyana Vinogradova ${ }^{3}$ \\ ${ }^{1}$ Lomonosov Moscow State University, Leninskie Gory, 1, 119991, Moscow, Russia \\ ${ }^{2}$ Melnikov Permafrost Institute SB RAS, Merzlotnaya, 36, 677010, Yakutsk, Russia \\ ${ }^{3}$ Saint Petersburg State University, Universitetskaya nab, 7/9, 199034, St. Petersburg, Russia \\ ${ }^{4}$ State Hydrological Institute, 2nd line of Vasilyevsky Island, 23, 199004,St. Petersburg, Russia \\ ${ }^{5}$ Perm State University, st. Bukireva, 15, 614068, Perm, Russia
}

\begin{abstract}
The study assessed the possibility of using a deterministic distributed hydrological model Hydrograph to calculate the maximum discharge of catastrophic flood at the Magadanka River $\left(48.5 \mathrm{~km}^{2}\right.$, city of Magadan, North-East of Russia) in 2014. The model parameters were not calibrated but borrowed from previously performed regional modelling studies. To verify the Hydrograph model streamflow simulations with daily time step were carried out for the period 1971-2015. The median value of Nash-Sutcliffe efficiency was 0.42 for a period of 44 years, which, given the lack of a meteorological station within the catchment, made it possible to evaluate the results as satisfactory. For the catastrophic flood calculation, two types of precipitation data were used: hourly data on precipitation from the nearest weather station and distribution of precipitation for the watershed from the meteorological model WRF. The flood hydrographs were estimated for the initial and corrected sets of the model parameters. The initial set of the model parameters allowed for proper timing of the flood peak but underestimated "observed" maximum value. We introduced the decreasing correction coefficient to the infiltration parameter of the model to "stretch out" the peak and volume of hydrographs. The results have shown that combining the meteorological input from weather station and regional meteorological model may allow for successful flood simulations in ensemble mode.
\end{abstract}

\section{Introduction}

Climate change causes significant transformation of the hydrological cycle. In many regions of Russia, the increase in the proportion and intensity of rainfall [1] is observed leading to the growth of number and magnitude of floods. Magadan region is situated in the North-East of Russia and is one of the mostly flood-prone areas of the country. Distinctive features of this region are the severe climate conditions, widespread permafrost and very

\footnotetext{
*Corresponding author: viktoriiakurovskaia@gmail.com
} 
rare hydrometeorological observation network. The system of hydrological forecasts is not developed here.

Magadan city is the capital of the region. It is located at the Okhotsk sea coast and affected by monsoon climate. Floods cause significant economic damage, but the system of hydrological forecasts is not developed here. In 2014 hazardous flood hit the city; it became the highest one in the history of observations. The damage in Magadan was assessed as significant: the roads were destroyed, the bridges were in critical condition, private residential buildings and garages were washed away near the water bodies. Also, Magadan Thermal Power Plant, the apartment buildings in the Magadan city, the villages of the Olsky district and farmlands were flooded and the power lines were washed in some places [2]

The aim of the study was to apply a hydrological model to reconstruct the conditions of the hazardous flood in Magadan city based on two sources of meteorological data: weather station and WRF climate model and assess the possibility of development of forecast system based on coupled hydrometeorological modelling.

\section{Study area}

The study object is the Magadanka river watershed in Magadan city (area of $48.5 \mathrm{~km}^{2}$ ). The river flows into the Taui Bay of the Sea of Okhotsk and the hydrological gauge is located at an altitude of $132 \mathrm{~m}$ (Fig. 1). The average and maximum watershed elevations are 498 and $689 \mathrm{~m}$, respectively. At the meteorological station of Magadan city (the altitude is $115 \mathrm{~m}$, WMO index is 25913), the average annual air temperature is $-2.8{ }^{\circ} \mathrm{C}$ and the annual precipitation reaches $560 \mathrm{~mm}$ (1966-2015). The maximum daily precipitation at the Magadan station during the observation period was $108 \mathrm{~mm}$ in 2014.

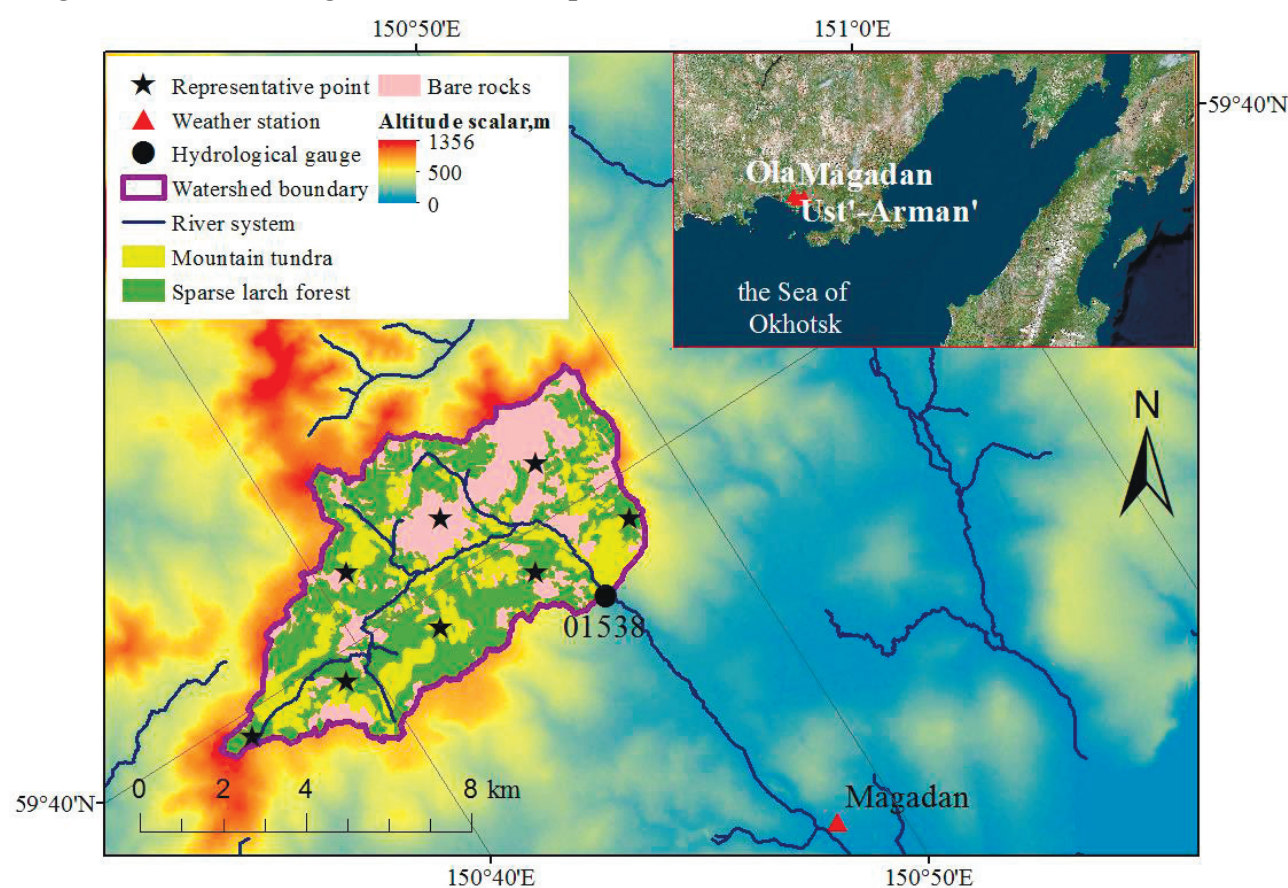

Fig. 1. Scheme of the Magadanka River watershed and distribution of runoff formation complexes. 
The study area is represented by the following landscapes: light coniferous larch forests, cedar brushwood, lichens and rocky talus. The soil cover varies from mountain permafrost-taiga soils to podzols on the coast. [3]. The catchment is located in the zone of discontinuous permafrost [3].

The Magadanka River streamflow is formed from snowmelt and rainfall, with rain floods are observed mainly in the summer-autumn period. Streamflow observations have been carried out since 1971. The average daily discharge for the period 1971-2017 was 0.78 $\mathrm{m}^{3} / \mathrm{s}$, the maximum instant water discharge reached $76.8 \mathrm{~m}^{3} / \mathrm{s}$ during the flood in 2014 .

\section{Hydrometeorological modelling}

In this study, the method of integrated hydrometeorological modelling was used. It was based on the combination of a distributed hydrological model Hydrograph [4-6] and a weather forecast model. The Hydrograph model was chosen as a research tool due to the possibility of using it to calculate and forecast runoff in the permafrost conditions, including the model adaptation results to the conditions of runoff formation in the Magadan region [7-8]. One of the main advantages of the Hydrograph model is the possibility of $a$ priori estimation of its parameters, representing the physical properties of landscapes. The Hydrograph model application implies the minimal use of parameter calibration methods, which is necessary when calculating and forecasting runoff under conditions of unsteady environment, when the hydrological regime is influence by both climate change and anthropogenic impact. The model has already been used before to calculate the maximum water discharge with mountain rivers on the Black Sea coast of the Caucasus and the Republic of Tuva as the study objects. The results were found to be satisfactory [9-11].

For runoff forecasting, data from the regional meteorological Weather Research and Forecasting (WRF) Model was used. WRF is one of the world's most widely used numerical weather prediction models [12]. It was designed to serve both research and operational needs. It is a free, open-source and constantly advancing model [13].

\section{Parametrization and verification of hydrological model}

In the system of the Hydrograph model, two types of watershed schematizations are implemented. Firstly, the watershed area is covered by the regular hexagon network. Representative Points (RP) are located in the nots of the network. For each RP, the characteristics of latitude, altitude, inclination and slope aspect, lag time from an RP to a gauging section by river network are estimated. It is assumed that each RP characterizes an elementary slope. Secondly, runoff formation complexes (RFC), similar to hydrological response units (HRU), which are unevenly distributed with the watershed, are extracted. The parameters of the model are estimated for each RFC. They consist of several main groups of the parameters, such as soil, vegetation, slope, groundwater [4-5,8,].

Previously the Hydrograph model was parameterized for the mountainous conditions of the Magadan region. The parameterization was carried out on the basis of long-term data from the Kolyma water-balance station [14]. The verification of the model was conducted for the basins of different sizes, from very small $\left(<1 \mathrm{~km}^{2}\right)$ to large ones (thousands of $\mathrm{km}^{2}$ ) $[4,7]$.

Three RFC were identified for the Magadanka River watershed using topographic maps of 1:25000 scale: rocky talus, mountain tundra on the southern slopes and sparse larch forest on the northern slopes (Fig. 1). Within the watershed, 11 RP were allocated and their characteristics were determined. Due to the similarity of natural conditions, the model parameters were borrowed from the studies [7]. For the Hydrograph model verification, 
continuous simulation of streamflow hydrographs of the Magadanka river with a daily step for the period 1971-2015 was carried out.

Average annual streamflow depth is about $770 \mathrm{~mm}$ for the Magadanka river. The amount of evapotranspiration at the watershed accounting for the coastal climate is estimated to be about $250 \mathrm{~mm}$. Considering that annual average value of precipitation at Magadan station is only $560 \mathrm{~mm}$, the residual of water balance is about $460 \mathrm{~mm}$. The correction factors were introduced when interpolating the precipitation in the RP. The model results included streamflow hydrographs and the values of the water balance elements. Given the introduced correction factors, the calculated annual streamflow was $820 \mathrm{~mm}$. The median value of the Nash-Sutcliffe (NS) performance criterion for daily water discharge reaches 0.42 , while the average, maximum and minimum values for this criterion are $0.2 ; 0.91$ and -1.24 respectively.

Figure 2 shows the example of two consequent years of simulations (2004-2005). In $2004 \mathrm{NS}$ is equal to 0.67 , annual precipitation and streamflow are 1300 and $1000 \mathrm{~mm}$, while in $2005 \mathrm{NS}$ is equal to -1.83 , annual precipitation and streamflow are 800 and 600 $\mathrm{mm}$ respectively. From the comparison at Fig. 2 it is obvious that the quality of simulated hydrographs crucially depends on the precipitation data. In some years the Magadan station data and introduced correction coefficients are representative, in other years introduced correction coefficients are insufficient. The results have shown that a snow precipitation is mostly uncertain and varies in wide range from one year to another. Simulated snowmelt freshet streamflow may perfectly coincide with observed series in one year and fail in magnitude and timing in the next year. Additional information such as snow routes data should be used to improve the snowmelt forecast.

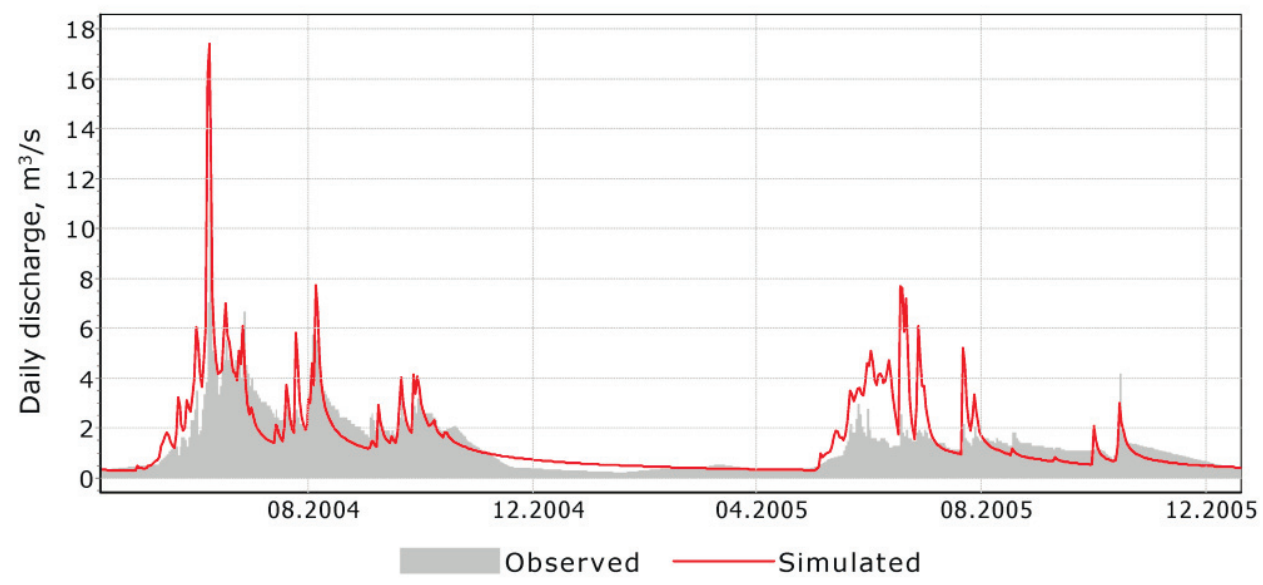

Fig. 2. Observed and simulated streamflow hydrographs: $2004-\mathrm{NS}=0.67 ; 2005-\mathrm{NS}=-1.85$.

\section{Estimation of hazardous flood in Magadan city in 2014}

On July 22-23, 2014 rainfall amount reached $196 \mathrm{~mm}$ (108 and $88 \mathrm{~mm}$ per day, respectively) with a monthly July norm of $69 \mathrm{~mm}$. During 48 hours, in the areas near Magadan city, the observed rainfall was $225 \mathrm{~mm}$ (Ust'-Arman' weather station) and 149 mm (Ola weather station) (Fig. 1) [15]. The flood peak on the Magadanka River in the area of the ski base was recorded on July 23 at 4 a.m., observed water level was $162 \mathrm{~cm}$ [15]. The river covered the whole floodplain, its width reached $40 \mathrm{~m}$ with the usual $7-10 \mathrm{~m}$ (rarely $15 \mathrm{~m}$ ) [17]. The maximum instant discharge (historical value) was estimated from 
the marks of high water levels and was $76.8 \mathrm{~m}^{3} / \mathrm{s}$, the average daily discharge during the flood was $38.1 \mathrm{~m}^{3} / \mathrm{s}$. One should take into account the uncertainty of observed maximum value considering the method of its estimation.

For the catastrophic flood calculation, we used two types of precipitation data: 1) detailed precipitation information from the rain gauge from the Magadan weather station; 2) precipitation values for all RPs based on the calculation according to the WRF model. The sum of precipitations according to the rain gauge for the period from 21.07 8:30 a.m. to 23.07 11:40 a.m. was $202 \mathrm{~mm}$ (Fig. 3, 2 pink), while the precipitation according to the WRF model for the same period was $258 \mathrm{~mm}$ (Fig. 3, 1 blue). As the precipitation data from the station was interpolated to RPs, the value $202 \mathrm{~mm}$ accounts for the introduced correction coefficients.

Fig. 3 presents four hydrographs of 2014 flood which were simulated with two types of meteorological input. The hydrographs 3 and 4 (Fig. 3) are estimated based using the set of model parameters which were verified on the historical period. One may see that the hydrograph 3 (WRF data) reaches $55.3 \mathrm{~m}^{3} / \mathrm{s}$, while the hydrograph 4 (weather station data) amounts only to $35 \mathrm{~m}^{3} / \mathrm{s}$. Both maximum values do not reach the "observed" value but coincide with the timing of flood peak. The hydrographs 5 and 6 (Fig. 3) are simulated with the correction coefficient 0.3 introduced to the parameter of soil infiltration (infiltration rate was proportionally decreased by the factor 0.3 in all RFC). One may see that the shape and timing of the hydrographs has changed significantly. The maximum values amounted to 120 and $80 \mathrm{~m}^{3} / \mathrm{s}$, the volume of flood increased twice, the timing of flood peak moved to $12 \mathrm{~h}$ earlier than it was observed.

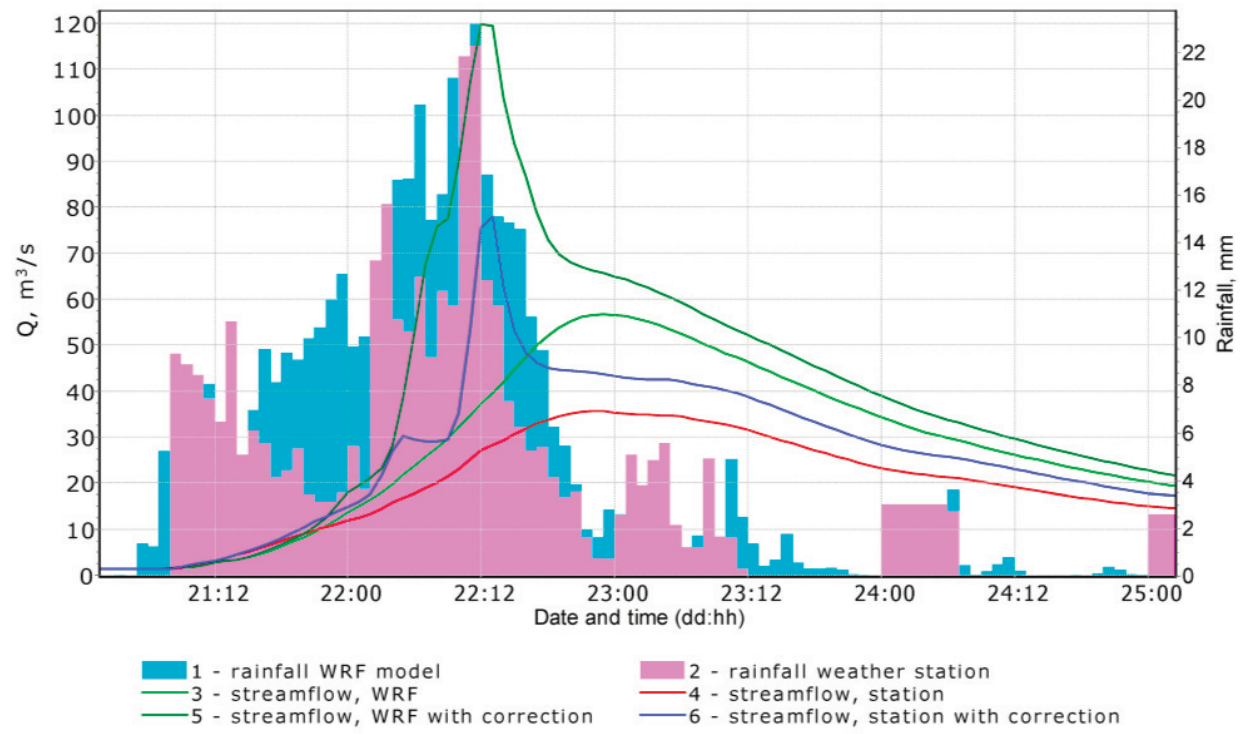

Fig. 3. Streamflow simulation results with hourly increments according to the pluviograph at Magadan weather station and the WRF meteorological model.

\section{Conclusions}

The study assessed the possibility of using a deterministic distributed hydrological model Hydrograph to calculate the maximum discharge of catastrophic flood at the Magadanka River (city of Magadan, North-East of Russia) in 2014. The model parameters were not calibrated, but were borrowed from previously performed regional modelling studies. 
Streamflow simulations with daily time step were carried out for the period from 1971 to 2015. The median value of NS was 0.42 for a period of 44 years, which, given the lack of a meteorological station within the catchment, made it possible to evaluate the results as satisfactory.

For the catastrophic flood calculation, two types of precipitation data were used: hourly data on precipitation from a weather station and distribution of precipitation for the watershed from the WRF model. The flood hydrographs were estimated for the initial and corrected sets of the model parameters. The initial set of the model parameters allowed for proper timing of the flood peak but underestimated "observed" maximum value. We introduced the decreasing correction coefficient to the infiltration parameter of the model to "stretch out" the peak and volume of hydrographs.

To conclude on the results, we suggest that the correction of the set of the model parameters should be carried out. The detailed data on hourly precipitation should be used to set up the model for the formation of the floods of high magnitude. In general, the results have shown that combining the meteorological input from weather station and regional meteorological model may allow for successful flood simulations in ensemble mode.

The study was carried out with the support of the RFBR (the research project №19-35-90090).

\section{References}

1. A. Chernokulsky, F. Kozlov, O. Zolina, I. Mokhov, V. Semenov, Environ. Res. Lett., 14 (2019)

2. Koluma.ru New of Magadan and Magadan Region URL: https://www.kolyma.ru/index.php?newsid=37430 (Accessed: 25.03 .2020 )

3. Surface water resources of the USSR, 19, 602 (1973)

4. Yu. Vinogradov, O. Semenova, T. Vinogradova, Hydrol. Process, 25, 1055-1073 (2011)

5. Yu. Vinogradov, T. Vinogradova, Matematicheskoe modelirovanie v gidrologii, 544 (2010)

6. O. Semenova, Yu. Vinogradov, T. Vinogradova, L. Lebedeva, Permafrost and Periglac. Process 25 , 257-269 (2014)

7. O. Makarieva, L. Lebedeva, T. Vinogradova, Kriosfera Zemli, 1, 43-56 (2020)

8. O. Semenova, L. Lebedeva, Yu. Vinogradov, Hydrogeol J., 21, 107-119 (2013)

9. O. Makarieva, N. Nesterova, T. Vinogradova, , I. Beldiman, A. Kolupaeva, Vestnik of St. Petersburg Univ. Earth Sc., 64, 24-43 (2019)

10. O. Makarieva, N. Nesterova, G. Yampolsky, E. Kudymova, A. Ostashov, A. Kolupaeva, Engin. Survey, 13, 36-51 (2019)

11. O. Makarieva, T. Vinogradova, N. Nesterova, A. Vinogradov, I. Beldiman, A. Kolupaeva, Georisk, 12 ,78-89 (2018)

12. W. Skamarock, J. Klemp, J. Dudhia, D. Gill, D. Barker,M. Duda, J. Powers, A descrip. of the Advanced Research WRF version 3, 125 (2018)

13. J. Powers, J. Klemp, W. Skamarock, C. Davis, J. Dudhia, D. Gill, J. Coen, D. Gochis, Bull. Amer. Meteor. Soc., 98, 1717-1737 (2017)

14. O. Makarieva, N. Nesterova, L. Lebedeva, S. Sushansky, Earth Syst. Sci. Data, 10, 689-710 (2018)

15. Ministry of Natural Resources and Ecology of the Magadan, Region Report on the environmental situation in the Magadan region in 2014, 74 (2015)

16. B. Vazhenin, Technosphere Security Technologies, 60, 1-14 (2015) 